AperTO - Archivio Istituzionale Open Access dell'Università di Torino

\title{
Auditory evoked potentials might have the potential to serve as early indicators related to amyloid beta peptide toxicity
}

\section{This is the author's manuscript}

Original Citation:

Availability:

This version is available http://hdl.handle.net/2318/1841580

since 2022-02-17T16:42:47Z

Published version:

DOI:10.1016/j.advms.2020.02.001

Terms of use:

Open Access

Anyone can freely access the full text of works made available as "Open Access". Works made available under a Creative Commons license can be used according to the terms and conditions of said license. Use of all other works requires consent of the right holder (author or publisher) if not exempted from copyright protection by the applicable law. 
in Medical Sciences

Elsevier Editorial System(tm) for Advances

Manuscript Draft

Manuscript Number: ADVMS-D-19-00290R2

Title: Auditory evoked potentials might have the potential to serve as early indicators related to amyloid beta peptide toxicity

Article Type: Original Article / Research

Keywords: Alzheimer's Disease; amyloid beta peptide; auditory evoked potentials; gamma oscillation; rat

Corresponding Author: Mr. enis hidisoglu,

Corresponding Author's Institution: Akdeniz University

First Author: enis hidisoglu

Order of Authors: enis hidisoglu; Piraye Yargicoglu

Abstract: Purpose: Accumulation of amyloid beta $(A \square)$ is thought to be the major cause of the development and progression of Alzheimer's disease (AD). The aim of this study is to elucidate the effects of Aß1-42 at increasing concentrations on auditory evoked potentials (AEPs) and to determine possible changes relevant to the accumulation of A $1-42$. Materials and Methods: In this study, rats were randomized to following groups ( $\mathrm{n}=10$ rats per each group): Sham $(0.9 \% \mathrm{NaCl})$ and $\mathrm{A} \beta-1(1 \mu \mathrm{g} / \mu \mathrm{l})$, $A \beta-2(2 \mu \mathrm{g} / \mu 1), A \beta-3(3 \mu \mathrm{g} / \mu \mathrm{l}), A \beta-4(4 \mu \mathrm{g} / \mu 1), A \beta-5(6 \mu \mathrm{g} / \mu 1), A \beta-6(8 \mu \mathrm{g} / \mu \mathrm{l})$ and $A \beta-7(10 \mu \mathrm{g} / \mu \mathrm{l})$ groups obtained by injection of $5 \mu \mathrm{l}$ per ventricle. Then, AEPs were recorded in freely-moving rats. Latencies and amplitudes of AEPs, evoked power, inter-trial phase synchronization, and auditory evoked gamma responses were obtained in response to auditory stimulus. Furthermore, $A \beta 1-42$ levels were determined in the temporal cortex. Results: A 1-42 levels were significantly higher in the temporal cortex in $A \beta$ groups compared to the Sham. In frontal and parietal regions, P1N1 amplitudes were significantly decreased in $A \square-3,4,5$ and 6 groups, and N1P2 amplitudes were significantly decreased in all A groups, whereas in temporal regions, P1N1 and N1P2 amplitudes were decreased in A $\square-2$, $3,4,5,6$ and 7 compared to the Sham. In the evoked gamma power and phase synchronization of gamma responses, we detected significant decrement after $A-4$ group, whereas a significant decrement in the filtered gamma responses was observed in A groups compared to the sham.

Conclusions: AEPs might be used as a biomarker to determine the $A \beta 1-42$ related neuronal degeneration in the auditory networks. 
Title: Auditory evoked potentials might have the potential to serve as early indicators related to amyloid beta peptide toxicity

\section{Enis Hidisoglu* and Piraye Yargicoglu}

Akdeniz University Faculty of Medicine Department of Biophysics, Antalya, TURKEY

*Corresponding Author: Enis Hidisoglu

Department of Biophysics, Akdeniz University Faculty of Medicine, Dumlupinar Boulevard TR-07058 Campus, Antalya, Turkey

Phone:

Work: 0 090-242-2493443

Fax: 0 090-242-2274495

e-mail: enishidisoglu@akdeniz.edu.tr

The author contribution

Study design: Enis Hidisoglu, Piraye Yargicoglu

Data collection: Enis Hidisoglu

Statistical analysis: Enis Hidisoglu

Data interpretation: Enis Hidisoglu, Piraye Yargicoglu

Manuscript Preparation: Enis Hidisoglu

Literature Search: Enis Hidisoglu, Piraye Yargicoglu

Funds Collection: Enis Hidisoglu 


\begin{abstract}
Purpose: Accumulation of amyloid beta $(\mathrm{A} \beta)$ is thought to be the major cause of the development and progression of Alzheimer's disease (AD). The aim of this study is to elucidate the effects of $A \beta_{1-42}$ at increasing concentrations on auditory evoked potentials (AEPs) and to determine possible changes relevant to the accumulation of $\mathrm{A} \beta_{1-42}$.

Materials and Methods: In this study, rats were randomized to following groups $(n=10$ rats per each group): Sham $(0.9 \% \mathrm{NaCl})$ and $\mathrm{A} \beta-1(1 \mu \mathrm{g} / \mu \mathrm{l}), \mathrm{A} \beta-2(2 \mu \mathrm{g} / \mu \mathrm{l}), \mathrm{A} \beta-3(3 \mu \mathrm{g} / \mu \mathrm{l}), \mathrm{A} \beta-$ $4(4 \mu \mathrm{g} / \mu 1), \mathrm{A} \beta-5(6 \mu \mathrm{g} / \mu \mathrm{l}), \mathrm{A} \beta-6(8 \mu \mathrm{g} / \mu \mathrm{l})$ and $\mathrm{A} \beta-7(10 \mu \mathrm{g} / \mu \mathrm{l})$ groups obtained by injection of 5 $\mu 1$ per ventricle. Then, AEPs were recorded in freely-moving rats. Latencies and amplitudes of AEPs, evoked power, inter-trial phase synchronization, and auditory evoked gamma responses were obtained in response to auditory stimulus. Furthermore, $A \beta_{1-42}$ levels were determined in the temporal cortex.
\end{abstract}

Results: $A \beta_{1-42}$ levels were significantly higher in the temporal cortex in $A \beta$ groups compared to the Sham. In frontal and parietal regions, P1N1 amplitudes were significantly decreased in $\mathrm{A} \beta-3,4,5$ and 6 groups, and N1P2 amplitudes were significantly decreased in all $\mathrm{A} \beta$ groups, whereas in temporal regions, P1N1 and N1P2 amplitudes were decreased in A $\beta-2,3,4,5,6$ and 7 compared to the Sham. In the evoked gamma power and phase synchronization of gamma responses, we detected significant decrement after A $\beta-4$ group, whereas a significant decrement in the filtered gamma responses was observed in $A \beta$ groups compared to the Sham.

Conclusions: AEPs might be used as a biomarker to determine the $A \beta_{1-42}$ related neuronal degeneration in the auditory networks.

Keywords: Alzheimer's disease; amyloid beta peptide; auditory evoked potentials; gamma oscillation; rat 


\section{Introduction}

Alzheimer's disease (AD) is a progressive and irreversible neurodegenerative disorder which gradually deteriorates memory and functional ability. The disease is characterized by two exclusive pathologies in the brain: accumulation of numerous amyloid plaques and neurofibrillary tangles, the former starts earlier than the latter $[1,2]$. These accumulated proteins, such as amyloid beta $(\mathrm{A} \beta)$ peptides, are intrinsically cytotoxic in vitro, and this accumulation stimulates synaptic loss, mitochondrial impairment, and apoptosis in neurons, causing ultimately deterioration of neural networks dynamics [3] and also responsible for early cognitive decline in $\mathrm{AD}$ patients [4-6]. Most of the current studies related to $\mathrm{AD}$ treatment have been focused at developing drugs that inhibit accumulation, clearance or toxicity of $A \beta$ peptide [7-9]. Unfortunately, there are no effective therapeutic modalities that are clinically beneficial, but if the possible changes in the neural network caused by the accumulation of $A \beta$ peptide can be detected in early stages of the disease, interventions may be developed to provide effective treatment of $\mathrm{AD}$ before permanent neurodegeneration occurs [10]. On the other hand, we need to underline that the findings of complementary therapies and some non-pharmacological studies such as brain stimulation techniques have promising outcomes on the treatment of AD related symptoms [11-13]. For clinical and experimental applications, electroencephalography (EEG) is a key technique to analyze the integrity of brain, sensory and/or cognitive systems and functional connectivity between different brain regions, and also the lowest cost and a noninvasive method [14-16]. Therefore, it is of great importance that the diagnosis of $\mathrm{AD}$ characterized by the accumulation of $\mathrm{A} \beta_{1-42}$ peptide and loss heavy of neuron and synapse in the cerebral cortex is detected by evaluating brain oscillations directly.

Brain oscillations have been reported to play a role in an important part of mechanisms underlying sensory and/or cognitive functions. These oscillations differ as magnitude and 
frequency depending on brain arousal state, their location and the exact nature of their neuronal network sources [17]. In the literature, spontaneous EEG and event-related potentials (ERPs) studies have been preferred generally in AD animal models, but there are not enough studies related to evoked potentials (EPs). In one of these studies, it has been reported that theta activity in spontaneous EEG was decreased, whereas beta and gamma activities were significantly increased in AD transgenic mouse models [18]. Pena-Ortega, (2013) also demonstrated that cerebral injection of $\mathrm{A} \beta$ peptide reduced theta activity by disturbing neuronal network dynamics, and ultimately caused cognitive dysfunction in animals [19]. In other studies, it was detected that the intracisternal injection of $A \beta$ did not have any effect spontaneous hippocampal theta activity, but caused to disturbed sensory evoked-induced theta activity [20]. In contrast, some studies argue that spontaneous EEG pattern is characterized by an increment at slow frequency components and a decrement at fast frequency components in AD animal models obtained by damaging cholinergic neurons, in addition to the decreased cholinergic activity and cognitive dysfunction [21]. In the light of these studies, it could be said that the $A \beta_{1-42}$ peptide caused to deterioration of neural network dynamics.

To illuminate the mechanism of causation of $\mathrm{AD}$, it is necessary to determine how $\mathrm{A} \beta_{1-42}$ peptide affects neural networks. To date, there is no study to evaluate the effects of $A \beta_{1-42}$ peptide injections into rat cerebral ventricles at increasing concentrations on auditory sensory networks have not been studied in awake rats. Considering the temporal lobe and associated cortices are the important brain regions among the main and early targets of $A \beta_{1-42}$ aggregates, and the neuronal oscillations are the phase-locked to the stimulus involved in the basis of EPs, it could be said that auditory evoked potentials (AEPs) might be used the detection of early electrophysiological changes induced by administration of aggregated $A \beta_{1-42}$ peptide. Also, there are a lot of studies which show that hearing loss might be associated with the development and progression of cognitive impairment and dementia or $\mathrm{AD}$, independent of 
age $[22,23]$, but it must be underlined that there is still no exact evidence of whether hearing loss associated with $\mathrm{AD}$ is a causal factor in dementia or is associated with temporal lobe pathologies. On the other hand, we consider that it has lower variability between subjects because sensory EPs do not require any cognitive processing and perception rather than ERPs, thus it may be more useful to detect $A \beta_{1-42}$ peptide related changes on auditory sensory networks via sensory EPs. Therefore, we aimed to determine whether there are any dose dependent effects of $A \beta_{1-42}$ peptide on auditory sensory networks and these possible changes might be used to predict for early signs of $A \beta_{1-42}$ peptide burden and localization in the brain. 


\section{Materials and Methods}

\subsection{Animals}

The rats were obtained from Akdeniz University Animal Care Unit. Male albino Wistar rats aged 3 months, weighing 250 to $300 \mathrm{~g}$ were housed in stainless steel cages and given food and water ad libitium. Animals were maintained at 12-h light-dark cycles and a constant temperature of $23 \pm 1^{\circ} \mathrm{C}$ at all times. The study design was representative illustrated in Fig. 1.

\subsection{Ethical Approval}

Ethical approval for this work was obtained from Akdeniz University Local Committee on Animal Research Ethics (Ethics Approval Date and Number: 09.11.2015/2015.01.11-3). All experimental protocols conducted on rats were performed in accordance with the standards established by the Institutional Animal Care and Use Committee at Akdeniz University.

\subsection{Animal Preparation}

All rats had five days handling. Following handling sessions, the animals were randomly divided into eight groups ( $\mathrm{n}=10$ per group); 7 AD groups obtained by intracerebroventricular (i.c.v.) injection of $A \beta_{1-42}$ peptide $(A \beta-1, A \beta-2, A \beta-3, A \beta-4, A \beta-5, A \beta-$ 6 and $\mathrm{A} \beta$-7) in different concentrations $(1 \mu \mathrm{g} / \mu \mathrm{l}, 2 \mu \mathrm{g} / \mu \mathrm{l}, 3 \mu \mathrm{g} / \mu \mathrm{l}, 4 \mu \mathrm{g} / \mu \mathrm{l}, 6 \mu \mathrm{g} / \mu \mathrm{l}, 8 \mu \mathrm{g} / \mu \mathrm{l}$, and $10 \mu \mathrm{g} / \mu \mathrm{l}$, respectively) and a sham group $(0.9 \% \mathrm{NaCl})$. The rat model of $\mathrm{AD}$ was established as described previously $[24,25] . \mathrm{A} \beta_{1-42}$ peptide (Sigma, USA) was injected into the lateral ventricles of the rats $(5 \mu \mathrm{l}$ per ventricle for each group). Stock solutions with different concentrations $(1 \mu \mathrm{g} / \mu \mathrm{l}, 2 \mu \mathrm{g} / \mu \mathrm{l}, 3 \mu \mathrm{g} / \mu \mathrm{l}, 4 \mu \mathrm{g} / \mu \mathrm{l}, 6 \mu \mathrm{g} / \mu \mathrm{l}, 8 \mu \mathrm{g} / \mu \mathrm{l}$, and $10 \mu \mathrm{g} / \mu \mathrm{l})$ were prepared in sterile normal saline. To obtain the aggregated form of $A \beta_{1-42}$, the stock solutions were then incubated at $37^{\circ} \mathrm{C}$ for three days before use.

\subsection{Surgery protocols}


The details of surgical protocols have been described previously [26]. In briefly, rats were anesthetized with a mixture of ketamine-based anesthetics (ketamine [50 mg/kg] and xylazine $[10 \mathrm{mg} / \mathrm{kg}$ ], intraperitoneally (i.p.)) and fixed on a stereotaxic instrument. Stainless steel screw electrodes were implanted bilaterally over the frontal (AP: $4.5 \mathrm{~mm}, \mathrm{ML}:+2$ and -2 $\mathrm{mm}$ ), parietal (AP: $-4.5 \mathrm{~mm}$, ML: +3.5 and $-3.5 \mathrm{~mm}$ ), temporal (AP: $-8.0 \mathrm{~mm}$, ML: +6.6 and $6.6 \mathrm{~mm}$ ) and occipital (AP: $-8.0 \mathrm{~mm}, \mathrm{ML}:+4.1$ and $-4.1 \mathrm{~mm}$ ) regions, and the reference electrode was inserted into the cerebellum (AP: $-12.72 \mathrm{~mm}$, ML: $2.5 \mathrm{~mm}$ ). Following chronically electrode implantation, either $A \beta_{1-42}$ peptide or saline $(0.9 \% \mathrm{NaCl})$ was injected into the lateral ventricles (injected coordinates: AP: $-0.8 \mathrm{~mm}$, ML: $-1.4 \mathrm{~mm}$ and $+1.4 \mathrm{~mm}$, DV: $-4.0 \mathrm{~mm}$ ) at $1 \mu \mathrm{l} /$ minute using a Hamilton microsyringe. After administration of solutions and electrode implantation, 1 week was allowed for recovery. After surgery, an otoscopic examination was performed to evaluate tympanic membrane damage before AEPs recordings. No tympanic damage was found in the rats. During recovery, the rats were housed in individual cages with free access to food and water.

\subsection{Electrophysiological recordings}

The details of electrophysiological recordings have been described previously [26]. In briefly, for the recordings from free-moving rats, chronically implanted electrodes were used. All electrode impedances were less than $10 \mathrm{kOhm}$. The EEG signal was amplified (Brainamp EEG/EP Amplifier, Brain Products, Munich, Germany), band-pass filtered (0.1-300 Hz) and digitized at a $1000 \mathrm{~Hz}$ sampling rate (Brainvision Recorder, Brain Products, Munich, Germany). AEPs were recorded using tones of $8000 \mathrm{~Hz}$ at the $85 \mathrm{~dB}$. The repetition rate of auditory stimulus was $1 \mathrm{~Hz}$. The duration of the $85-\mathrm{dB}$ tones was $50 \mathrm{~ms}$ and the tones were presented through a loudspeaker at a distance of approximately $15 \mathrm{~cm}$ from the ear of the rat. The EEG data were processed in $1000 \mathrm{~ms}$ epochs $(500 \mathrm{~ms}$ pre-stimulus/500 ms poststimulus). The averaging of 100 responses were performed with a BrainVision Analyzer 
(Brain Products GmBH). Peak latencies of the components were measured from the stimulus artifact to the peak in milliseconds. Amplitudes were measured as the voltage between successive peaks. Measurements were made on one negative (N1) and two positive (P1, P2) potentials which are seen in all groups.

\subsection{Data analysis}

\subsubsection{Event-related spectral perturbations (ERSP) analysis}

Time-frequency analysis was applied for all epochs between 4 to $48 \mathrm{~Hz}$ using Morletbased wavelets transform with 3 cycles and within 2 ms- sliding windows between -500 to $500 \mathrm{~ms}$ (EEGLAB) [27]. Spectral analysis was computed on the wavelet-transformed epochs for each stimulus at each time point and wavelet frequency to yield time-frequency maps. The color at each image pixel indicates amplification (in $\mathrm{dB}$ ) at a given frequency and latency to the time locking stimulus. Spectral analysis was used to determine the dominant frequencies in the AEPs during the experiment. The peak powers at $28-48 \mathrm{~Hz}$ individual frequency were extracted for statistical assessment. Therefore, we used each rat's peak power at the gamma frequency band.

\subsubsection{Inter-trial coherence (ITC) analysis}

Inter-trial coherence (ITC) indicates that the EEG activity at a given time and frequency in single trials becomes phase-locked. The ITC measure takes values between 0

and 1. A value of 0 represents absence of synchronization between EEG data and the time locking stimulus; a value near 1 indicates phase synchronization. Here, we calculated the ITC using (EEGLAB) [27] as follows: For $\mathrm{j}=1$ to $\mathrm{N}$ trials,

$$
\operatorname{ITC}(t, f)=\left\|\frac{1}{N} \sum_{i=1}^{N} e^{j \varphi j(t, f)}\right\|
$$


where $\varphi j(t, f)$ is the phase of the wavelet at time $\mathrm{t}$ and frequency $\mathrm{f}$. All ITC values were baseline corrected over $-300 \mathrm{~ms}$ to $-50 \mathrm{~ms}$ and were computed each rat for grand average. We used each rat's peak-frequency at $28-48 \mathrm{~Hz}$ frequency band.

\subsubsection{Digitally filtered auditory evoked gamma oscillatory responses}

Digital filtering of AEPs was performed with BrainVision Analyzer software (Brain Products $\mathrm{GmBH}$ ). Each rat's averaged evoked responses were digitally filtered in the 28-48 $\mathrm{Hz}$ frequency range. The maximum peak-to-peak amplitudes for each rat's averaged gamma (28-48 Hz) responses were analyzed. The largest peak-to-peak value in these frequency ranges in terms of microvolt found in the time window between 0 and $200 \mathrm{~ms}$.

\subsection{Measurement of $A \beta_{1-42}$ peptide levels}

After the electrophysiologic recordings, the rats were deeply anesthetized (20\% urethane, $5 \mathrm{~mL} / \mathrm{kg}$, i.p.) and a cardiac cannula was placed. Brain tissues were perfused with heparinized isotonic (heparin (Innohep, Leo Pharma, Denmark), anticoagulant, and isotonic solution $(0.9 \% \mathrm{NaCl})$ were administered via the cannula. Temporal cortex was immediately dissected for enzyme-linked immunosorbent assay (ELISA) analysis. A $\beta_{1-42}$ levels in the supernatants of tissue lysates were measured using a commercially available ELISA kit (SensoLyte Anti-Mouse/Rat b-amyloid (1-42) Quantitative ELISA *Colorimetric*, AnaSpec, Fremnot, CA, USA) in accordance with the manufacturer's instructions.

\subsection{Statistical analysis}

All statistical analyses were performed using SPSS 18.0 (SPSS, Chicago, IL, USA) software for Windows. $A \beta_{1-42}$ levels were analyzed using analysis of variance (ANOVA). Post-hoc comparisons were analyzed using the Bonferroni test. A repeated measure of ANOVA was used to determine the statistical significance differences of latencies, peak-topeak amplitudes, spectrograms, ITC and filtered auditory evoked gamma power response to auditory stimulus over different locations and between the groups. During the analysis, 
repeated measures of ANOVA included the between-subjects factor as group (Sham, A $\beta-1$, $\mathrm{A} \beta-2, \mathrm{~A} \beta-3, \mathrm{~A} \beta-4, \mathrm{~A} \beta-5, \mathrm{~A} \beta-6$ and $\mathrm{A} \beta-7)$, and within-subject factors as 8 electrode sites (FrA1, FrA2, PtA1, PtA2, TeA1, TeA2, V1 and V2). Greenhouse-Geisser-corrected p values were reported. Results are expressed as mean \pm standard deviation (SD). Significance levels were set at $\mathrm{p}<0.05$. 


\section{Results}

The animals were apparently in good condition during experiment. No significant difference could be observed in the body weight change among different experimental groups (data not shown).

\subsection{Results of $A \beta_{1-42}$ peptide levels}

ANOVA for $A \beta_{1-42}$ peptide levels revealed a significant treatment effect $[F(7.49)=$ 33,61, $\mathrm{p}<0.001]$. Values of $A \beta_{1-42}$ peptide levels in the temporal cortex (mean $\pm \mathrm{SD}$ ) in the sham and $A \beta_{1-42}$ treated groups are given in Fig. 2. Post-hoc comparison tests indicated that $A \beta_{1-42}$ peptide levels were significantly increased in all $A \beta_{1-42}$-injected groups compared to the sham group, and also there were significant increment in $A \beta-4,5,6$ and 7 groups compared with $A \beta-1$ group.

\subsection{Results of latency and amplitude values of AEPs}

P1, N1 and P2 components of AEPs for all experimental groups are presented in Fig. 3. Measurement was made on one negative and two positive potentials, which were seen in all of the groups. The means and SD of peak latencies of AEPs components of the all groups are shown in Tab. 1. There were found to be a significant effect of the electrode localization on all latencies values as a result of repeated ANOVA analysis $[\mathrm{F}(7,392)=12.71 ; \mathrm{F}(7,392$ )$=23.94 ; \mathrm{F}(7,392)=5.79 ; \mathrm{p}<0.001]$. Post-hoc comparisons of the electrode regions were found to have shorter latency values in the temporal and occipital regions than in the other regions $(\mathrm{p}<0,05)$. There were no significant changes in P1, N1 and P2 latency values between the experimental groups $[\mathrm{F}(7,56)=1.47 ; \mathrm{F}(7,56)=0.96 ; \mathrm{p}>0.05]$.

The means and SD of peak-to-peak amplitudes of AEPs components of the all groups are shown in Tab. 2. In the result of repeated ANOVA, it was determined significant difference between electrode regions for maximum peak-to-peak P1N1 and N1P2 amplitudes $[\mathrm{F}(7,392)=51.31 ; \mathrm{F}(7,392)=31.53 ; \mathrm{p}<0.001]$. Post-hoc comparisons revealed that the P1N1 
response was in the lowest in the occipital regions and the N1P2 response was in the highest temporal regions. Furthermore, there was also observed a significant interaction effect for location $\times$ group in maximum peak-to-peak P1N1 and N1P2 amplitudes $[\mathrm{F}(49,56)=3.56$ $\mathrm{p}<0.001 ; \mathrm{F}(49,56)=1.59 ; \mathrm{p}<0.01]$, thus showing that the observed differences between groups were not found in all regions. For more detailed information about the differences in the both interaction effects and between the groups, the changes in P1N1 and N1P2 amplitudes were analyzed separately for different electrode regions. In a more detailed analysis, it were observed that a statistically significant decrement in the P1N1 amplitude at the frontal and parietal regions in the $\mathrm{A} \beta-3,4,5$, and 6 groups, and at the temporal regions in the $\mathrm{A} \beta-2,3,4$, 5, 6, and 7 groups compared with Sham group. A significant decrement were detected in N1P2 amplitude at the frontal and parietal regions in all $\mathrm{A} \beta$ groups, and at the temporal regions in $\mathrm{A} \beta-2,3,4,5,6$ and 7 groups compared with Sham group. No significant differences were detected both P1N1 and N1P2 amplitudes at the occipital regions in the all groups.

\subsection{Results of event-related spectral perturbations (ERSP)}

Fig. 4 illustrates the grand average of time-frequency planes showing the poststimulus enhancement of gamma responses in auditory stimulus for sham and all $\mathrm{A} \beta$ groups at TeA1 location. The means and standard deviations of maximum gamma band spectrograms values of AEPs in all groups are shown in Tab. 3. The grand average of the ERSP values indicates that the auditory stimulus results in a strong gamma-response power within $100 \mathrm{~ms}$ following stimulation in both sham and $A \beta_{1-42}$ treated groups, but stronger in the sham group. In the result of repeated ANOVA, there was no significant location x group interaction, and therefore differences between groups were examined independently of electrode location. Post-hoc comparisons indicated that gamma response power is significantly reduced in the 
$\mathrm{A} \beta-4,5,6$ and 7 groups compared to the sham group $(\mathrm{p}<0.001)$ and in the $A \beta 7$ group compared to the $A \beta 1$ group $(\mathrm{p}<0.001)$.

\subsection{Results of event-related inter-trial coherence (ITC)}

Fig. 5 illustrates the grand average of time-frequency planes showing the ITC of gamma responses in auditory stimulus for sham and all $\mathrm{A} \beta$ groups at TeA1 location. The means and standard deviations of maximum gamma band ITC values of AEPs in all groups are shown in Tab. 4. Results indicates that, in the $0-100 \mathrm{~ms}$ time window, auditory stimulus leads to a strong gamma-phase lock in both sham and $A \beta_{1-42}$ treated groups, but stronger in the sham group. In the result of statistical analysis, it was observed significant differences between groups $[F(7,49)=9.49 \mathrm{p}<0.001]$, but there was no significant differences at location $\mathrm{x}$ group interaction. Therefore, the observed differences between groups were examined independently of electrode location. Post-hoc comparisons indicated that gamma phase locking values were significantly reduced in the $A \beta-4,5,6$ groups compared to the sham and $A \beta 1$ groups and in the $A \beta-7$ compared to the sham and $A \beta-1,2,3$ groups.

\subsection{Results of digitally filtered auditory evoked gamma oscillatory responses}

Fig. 6 illustrates the grand average of filtered $(28-48 \mathrm{~Hz})$ gamma responses of sham and all $A \beta_{1-42}$ treated groups at TeA1 location. The means and standard deviations of filtered $(28-48 \mathrm{~Hz})$ auditory evoked gamma oscillatory responses values in all groups are shown in Tab. 5. Repeated ANOVA indicated that there were significant alteration between groups $[F(7,56)=13.52 \mathrm{p}<0.001]$, electrode location $[\mathrm{F}(7,392)=45.91 \mathrm{p}<0.001]$, and location $\mathrm{x}$ group interaction $[\mathrm{F}(49,56)=5.78 \mathrm{p}<0.001]$. Post-hoc comparisons revealed that evoked gamma responses were decreased in all $A \beta_{1-42}$ treated groups compared to sham in frontal, parietal and occipital, but there was no significant changes among $A \beta_{1-42}$ treated groups. In temporal region, evoked gamma responses were decreased in all $A \beta_{1-42}$ treated groups compared to 
sham, and also there were significant reductions in $A \beta-7$ group compared to other $A \beta_{1-42}$ treated groups. 


\section{Discussion}

In our previous study, we reported that spontaneous delta activity is altered only after a significant accumulation of $A \beta_{1-42}$, whereas all concentrations of $A \beta_{1-42}$ peptide (between 1 and $10 \mu \mathrm{g} / \mu \mathrm{l} \times 5 \mu \mathrm{l}$ per each ventricle) have effects characterized by a reduction in the spontaneous gamma activity. Also, we observed that i.c.v. application of $A \beta_{1-42}$ peptide has led to AD-like memory deficits in the rats [26]. In this study, AEPs were recorded from the freely moving rats to examine the effect of $A \beta_{1-42}$ peptide on the sensory system and to determine the possible associated biomarkers depending on the accumulation of $A \beta_{1-42}$ peptide. For this purpose, we used the same AD rat model which is based on i.c.v. injection of aggregated $A \beta_{1-42}$ peptide into the animal brain as in our previous study.

To determine $A \beta_{1-42}$ peptide induced alterations in AEPs, peak latency and peak-topeak amplitude values of responses to auditory stimuli were calculated for each group. Examining the responses to auditory stimuli, it was observed that there was no statistically significant difference between groups in peak latency of AEPs. These findings clearly indicate that the rate of auditory information processing is not affected by the application of $A \beta$ peptide. In consistent with our results, it has been indicated that latencies of auditory sensory components did not change in EPs recorded from AD patients [28]. On the other hand, examining the peak-to-peak amplitude of the responses to auditory stimuli, it was found that there were statistically significant differences in the amplitude of AEPs. As previously reported, the P1N1 amplitude is associated with physical properties such as early sensory functions and the intensity, frequency, spectral and temporal characteristics of the stimulus, and the N1P2 amplitude is associated with later sensory functions such as processing and interpretation of auditory information [29]. Thus, our results indicate that the administration of $\mathrm{A} \beta_{1-42}$ peptide leads to deterioration of the sensory system integrity. The significant amplitude changes in AEPs also point out that the administration of $A \beta_{1-42}$ peptide may 
reduce the amount of neuronal populations actively engaged in these processes or deteriorate synchronously firing properties of neurons and causes neurodegeneration in stimulus related regions. Since the temporal cortex and associated regions are more sensitive to the neurodegeneration than other brain regions in the early stages of $\mathrm{AD}$, auditory evoked responses are expected to be more affected in the temporal cortex and associated regions.. Consequently, the sensitivity emerging in the temporal regions is thought to be related to the modality of the stimulus which is used rather than the $A \beta$ burden, besides it would potentially be a useful biomarker to detect early degeneration related to $A \beta_{1-42}$ peptide.

On the other hand, as known, the EEG consists of the summed electrical activities of generator neuronal clusters with rhythmic activity in many frequency bands. These brain oscillations are called spontaneous brain activity resulting from a completely random activity. However, a sensory stimulus can induce synchronization in the activity of these neuronal clusters. This synchronization provides occurrence of evoked responses which have a certain pattern and time in the brain. Hence, it could be concluded that these evoked responses, representing the temporal activity of neuronal clusters, are originated from the transitions from the irregular activity of neuronal clusters to regular activity related to stimulus [30, 31]. One of these oscillations is the gamma band $(30-70 \mathrm{~Hz})$ oscillation. Gamma oscillation is a multifunctional brain activity that can be selectively observed in different subcortical and cortical regions; as opposed to representing a specific function of the central nervous system rather than the other frequency bands. Specifically, it is thought to be involved in information processing in cortical networks [32]. In the literature, is has been shown that the gamma oscillation synchronization is an important and fundamental process for brain function, which emerges within the first $150 \mathrm{~ms}$ following stimulation [33, 34]. In human studies, researchers also reported that synchronization of neural activity was disturbed in AD patients, which observed reduced functional communication within and between cortical regions [35]. In 
particular, the early stages of $\mathrm{AD}$ have been characterized by a decrement in functional connectivity between specific brain regions related to cognition [36].

We detected i.c.v. application of $A \beta_{1-42}$ peptide has caused significant changes in the auditory evoked responses. Especially, the most obvious changes between groups were observed in the gamma band $(28-48 \mathrm{~Hz})$, which emerges within the first $100 \mathrm{~ms}$ following stimulation. $A \beta$ groups have a trend to display lower auditory evoked gamma response than the sham group. Despite the fact that no regional differences in the gamma activity depending on the accumulation of $A \beta_{1-42}$ peptide have been noticed, it has caused similar changes in ERSP and ITC values, and progressive decrement was observed in auditory evoked gamma responses in power and in phase synchrony upon presentation of stimulation in $A \beta$ groups than the sham group. Also, this decrement did not reach a significant level in the group comparisons up to $4 \mu \mathrm{g} / \mu 1$ concentration of $\mathrm{A} \beta_{1-42}$ peptide $\mathrm{x} 5 \mu 1$. On the other hand, it has been detected that there is a statistically significant relationship between alteration of gamma oscillation and accumulation of $A \beta$ peptide. In a study, it was observed that the accumulation of $A \beta$ peptide was decreased by modulation of gamma oscillations. The possible cause of this decrement was reported to be suppressed amyloidogenesis and improved amyloid endocytosis due to microglial activation [37]. Additionally, gamma oscillations are known to occur by the synchronous activity of excitatory and inhibitory (E/I) synaptic interactions in the brain [38, 39]. These E/I synaptic interactions have been reported to be affected by the accumulation of hyperphosphorylated tau peptides and $\mathrm{A} \beta$ peptide, the most important neuropathological markers of $\mathrm{AD}[40,41]$. In addition, it was reported that transcranial magnetic stimulation (TMS) techniques have an important role in the detailed assessment of the neurophysiological mechanisms underlying $\mathrm{AD}$. As a result of these studies, it is hypothesized that $\mathrm{AD}$ is thought to be a complex neurodegenerative disease involving different neurotransmitter systems [42]. On the other hand, the findings of some TMS studies indicated that the resting motor 
threshold is generally reduced in $\mathrm{AD}$, which is interpreted as a marker of increased motor cortex excitability [43-45]. These results also support that an imbalance of E/I synaptic interactions in the cerebral cortex is observed in AD pathology. Considering all these findings, it is conceivable to conclude that the degeneration in these E/I synaptic interactions due to the accumulation of $A \beta$ peptide is likely to be the underlying cause of the reduction in the evoked gamma responses observed in this study. Moreover, it is likely to put forward that the $\mathrm{A} \beta_{1-42}$ peptide disrupts the synchronous activity between the neural clusters and eliminates the regularity associated with the sensory stimulation with the decreases observed in the ERSP and ITC values in the A $\beta$-treated groups with high doses.

\subsection{Limitations of the study}

The complexity of AD pathology is the main limitation of this study. The results of our study have been obtained from the rats which have only $\mathrm{A} \beta$ pathology, so the changes in AEPs are associated with the A $\beta$ pathology. However, considering the complex pathology and age-related hearing problems in AD patients, it seems not possible to say how the investigated parameters will change in AD patients. Thus, further studies, specifically human studies, are needed to obtain direct evidence about AD-related changes in the auditory sensory networks, and for clinical applications.

\section{Conclusions}

The changes induced by $A \beta_{1-42}$ peptide in the amplitude of AEPs indicate that the accumulation of $A \beta_{1-42}$ peptide has an important effect on auditory sensory system functions, and cause disruption in the integrity of sensory system. Moreover, the decrement of amplitude rather than latency empowers the idea that accumulation of $A \beta_{1-42}$ peptide leads to a decrement in the amount of neuronal population taking active roles in sensory processes, and thus neurodegeneration in the related regions rather than the rate of information transmission and processing. In addition, the findings of evoked gamma responses indicate that the $\mathrm{A} \beta_{1-42}$ 
peptide leading to a global effect in the brain can be examined by the evoked gamma power and phase synchrony, while $A \beta_{1-42}$ peptide location might be determined by evaluating the filtered gamma band responses due to observed regional differences in this activity. 


\section{References}

[1] Davies CA, Mann DMA, Sumpter PQ, Yates PO. A Quantitative Morphometric Analysis of the Neuronal and Synaptic Content of the Frontal and Temporal Cortex in Patients with Alzheimers-Disease. J Neurol Sci. 1987;78:151-64.

[2] Terry RD, Masliah E, Salmon DP, Butters N, DeTeresa R, Hill R, et al. Physical basis of cognitive alterations in Alzheimer's disease: synapse loss is the major correlate of cognitive impairment. Annals of neurology. 1991;30:572-80.

[3] Sakono M, Zako T. Amyloid oligomers: formation and toxicity of A beta oligomers. Febs J. 2010;277:1348-58.

[4] Galasko DR, Shaw LM. CSF biomarkers for Alzheimer disease - approaching consensus. Nat Rev Neurol. 2017;13:131-+.

[5] Karran E, Mercken M, De Strooper B. The amyloid cascade hypothesis for Alzheimer's disease: an appraisal for the development of therapeutics. Nat Rev Drug Discov. 2011;10:698U1600.

[6] Palop JJ, Mucke L. Amyloid-beta-induced neuronal dysfunction in Alzheimer's disease: from synapses toward neural networks. Nature neuroscience. 2010;13:812-8.

[7] Salloway S, Sperling R, Brashear HR. Phase 3 Trials of Solanezumab and Bapineuzumab for Alzheimer's Disease REPLY. New Engl J Med. 2014;370:1460-.

[8] Siemers ER, Sundell KL, Carlson C, Case M, Sethuraman G, Liu-Seifert H, et al. Phase 3 solanezumab trials: Secondary outcomes in mild Alzheimer's disease patients. Alzheimers Dement. 2016;12:110-20.

[9] Vandenberghe R, Rinne JO, Boada M, Katayama S, Scheltens P, Vellas B, et al. Bapineuzumab for mild to moderate Alzheimer's disease in two global, randomized, phase 3 trials. Alzheimers Res Ther. 2016;8. 
[10] Murphy C. Olfactory and other sensory impairments in Alzheimer disease. Nat Rev Neurol. 2019;15:11-24.

[11] Gonsalvez I, Baror R, Fried P, Santarnecchi E, Pascual-Leone A. Therapeutic Noninvasive Brain Stimulation in Alzheimer's Disease. Curr Alzheimer Res. 2017;14:362-76. [12] Lanza G, Centonze SS, Destro G, Vella V, Bellomo M, Pennisi M, et al. Shiatsu as an adjuvant therapy for depression in patients with Alzheimer's disease: A pilot study. Complementary therapies in medicine. 2018;38:74-8.

[13] Zhao J, Li Z, Cong Y, Zhang J, Tan M, Zhang H, et al. Repetitive transcranial magnetic stimulation improves cognitive function of Alzheimer's disease patients. Oncotarget. 2017;8:33864-71.

[14] Basar E. Brain dynamics and memory. Int J Psychophysiol. 2004;54:7-8.

[15] Basar E. Macrodynamics of electrical activity in the whole brain. Int J Bifurcat Chaos. 2004;14:363-81.

[16] Rossini PM, Rossi S, Babiloni C, Polich J. Clinical neurophysiology of aging brain: From normal aging to neurodegeneration. Prog Neurobiol. 2007;83:375-400.

[17] Mantini D, Perrucci MG, Del Gratta C, Romani GL, Corbetta M. Electrophysiological signatures of resting state networks in the human brain. P Natl Acad Sci USA. 2007;104:13170-5.

[18] Wang J, Ikonen S, Gurevicius K, van Groen T, Tanila H. Alteration of cortical EEG in mice carrying mutated human APP transgene. Brain Res. 2002;943:181-90.

[19] Pena-Ortega F. Amyloid Beta-Protein and Neural Network Dysfunction. Journal of neurodegenerative diseases. 2013;2013:657470.

[20] Pena-Ortega F, Solis-Cisneros A, Ordaz B, Balleza-Tapia H, Lopez-Guerrero JJ. Amyloid Beta 1-42 Inhibits Entorhinal Cortex Activity in the Beta-Gamma Range: Role of GSK-3. Curr Alzheimer Res. 2012;9:857-63. 
[21] Dringenberg HC. Alzheimer's disease: more than a 'cholinergic disorder' - evidence that cholinergic-monoaminergic interactions contribute to EEG slowing and dementia. Behav Brain Res. 2000;115:235-49.

[22] Deal JA, Betz J, Yaffe K, Harris T, Purchase-Helzner E, Satterfield S, et al. Hearing Impairment and Incident Dementia and Cognitive Decline in Older Adults: The Health ABC Study. J Gerontol a-Biol. 2017;72:703-9.

[23] Lin FR, Metter EJ, O'Brien RJ, Resnick SM, Zonderman AB, Ferrucci L. Hearing Loss and Incident Dementia. Arch Neurol-Chicago. 2011;68:214-20.

[24] Gong L, Li SL, Li H, Zhang L. Ginsenoside Rg1 protects primary cultured rat hippocampal neurons from cell apoptosis induced by beta beta-amyloid protein. Pharm Biol. 2011;49:501-7.

[25] Li YZ, Duffy KB, Ottinger MA, Ray B, Bailey JA, Holloway HW, et al. GLP-1 Receptor Stimulation Reduces Amyloid-beta Peptide Accumulation and Cytotoxicity in Cellular and Animal Models of Alzheimer's Disease. J Alzheimers Dis. 2010;19:1205-19.

[26] Hidisoglu E, Kantar-Gok D, Er H, Acun AD, Yargicoglu P. Alterations in spontaneous delta and gamma activity might provide clues to detect changes induced by amyloidadministration. Eur J Neurosci. 2018;47:1013-23.

[27] Delorme A, Makeig S. EEGLAB: an open source toolbox for analysis of single-trial EEG dynamics including independent component analysis. J Neurosci Methods. 2004;134:9-21.

[28] Goodin DS, Aminoff MJ. Electrophysiological Differences between Demented and Nondemented Patients with Parkinsons-Disease. Annals of neurology. 1987;21:90-4.

[29] Naatanen R, Paavilainen P, Alho K, Reinikainen K, Sams M. The mismatch negativity to intensity changes in an auditory stimulus sequence. Electroencephalography and clinical neurophysiology Supplement. 1987;40:125-31. 
[30] Gurtubay IG, Alegre M, Labarga A, Malanda A, Artieda J. Gamma band responses to target and non-target auditory stimuli in humans. Neuroscience letters. 2004;367:6-9.

[31] Yordanova J, Kolev V. Event-related alpha oscillations are functionally associated with P300 during information processing. Neuroreport. 1998;9:3159-64.

[32] Fries P, Nikolic D, Singer W. The gamma cycle. Trends in neurosciences. 2007;30:30916.

[33] Fries P. Neuronal Gamma-Band Synchronization as a Fundamental Process in Cortical Computation. Annu Rev Neurosci. 2009;32:209-24.

[34] Uhhaas PJ, Singer W. Neural synchrony in brain disorders: Relevance for cognitive dysfunctions and pathophysiology. Neuron. 2006;52:155-68.

[35] Grady CL, Furey ML, Pietrini P, Horwitz B, Rapoport SI. Altered brain functional connectivity and impaired short-term memory in Alzheimer's disease. Brain : a journal of neurology. 2001;124:739-56.

[36] Bokde ALW, Lopez-Bayo P, Meindl T, Pechler S, Born C, Faltraco F, et al. Functional connectivity of the fusiform gyrus during a face-matching task in subjects with mild cognitive impairment. Brain : a journal of neurology. 2006;129:1113-24.

[37] Iaccarino HF, Singer AC, Martorell AJ, Rudenko A, Gao F, Gillingham TZ, et al. Gamma frequency entrainment attenuates amyloid load and modifies microglia. Nature. 2016;540:230-+.

[38] Belluscio MA, Mizuseki K, Schmidt R, Kempter R, Buzsaki G. Cross-Frequency PhasePhase Coupling between Theta and Gamma Oscillations in the Hippocampus. J Neurosci. 2012;32:423-35.

[39] Traub RD, Whittington MA, Buhl EH, Jefferys JGR, Faulkner HJ. On the mechanism of the gamma ->beta frequency shift in neuronal oscillations induced in rat hippocampal slices by tetanic stimulation. J Neurosci. 1999;19:1088-105. 
[40] Daulatzai MA. Early Stages of Pathogenesis in Memory Impairment during Normal Senescence and Alzheimer's Disease. J Alzheimers Dis. 2010;20:355-67.

[41] Shen Z. Brain cholinesterases: II. The molecular and cellular basis of Alzheimer's disease. Med Hypotheses. 2004;63:308-21.

[42] Pennisi G, Ferri R, Lanza G, Cantone M, Pennisi M, Puglisi V, et al. Transcranial magnetic stimulation in Alzheimer's disease: a neurophysiological marker of cortical hyperexcitability. J Neural Transm (Vienna). 2011;118:587-98.

[43] Alagona G, Ferri R, Pennisi G, Carnemolla A, Maci T, Domina E, et al. Motor cortex excitability in Alzheimer's disease and in subcortical ischemic vascular dementia. Neuroscience letters. 2004;362:95-8.

[44] Ferreri F, Pauri F, Pasqualetti P, Fini R, Dal Forno G, Rossini PM. Motor cortex excitability in Alzheimer's disease: a transcranial magnetic stimulation study. Annals of neurology. 2003;53:102-8.

[45] Pennisi G, Alagona G, Ferri R, Greco S, Santonocito D, Pappalardo A, et al. Motor cortex excitability in Alzheimer disease: one year follow-up study. Neuroscience letters. 2002;329:293-6. 


\section{Figure Legends}

Fig. 1. A schematic flow chart of the experimental design.

Fig. 2. $A \beta 1-42$ peptide levels in the temporal cortex obtained using ELISA in all groups ( $n=8$ per group). A $\beta 1-42$ peptide levels were significantly increased in all $A \beta 1-42-$ injected groups compared to the sham group (***: $\mathrm{p}<0.001)$. Mean \pm SD values are given on the bar graph for each group.

Fig. 3. Grande average of AEPs waveforms evoked by auditory stimulus at the TeA1 electrode location. Different colors represent different groups. Time 0 is the stimulus onset and $\mathrm{N} 1$ is the first negative wave.

Fig. 4. Grand average of ERSP time-frequency matrices calculated by wavelet-based analysis of the averaged evoked potentials showing relative changes in total power compared with the baseline period at all electrode locations. Power (in $\mathrm{dB}$ ) is indicated by color code with warmer colors representing higher power values (color bar at the right side of each panel). It was found that a certain amount of $A \beta_{1-42}$ peptide leads to a decrease in gamma-band power compared to the Sham group.

Fig. 5. Grand average of time-frequency plots showing phase-locking (ITC) values for auditory stimulus at all electrode locations. Phase-locking is indicated by color code with warmer colors representing higher phase stability across trials (color bar at the right side of each panel). ITC was detected to be affected by injection of $A \beta_{1-42}$.

Fig. 6. Grand average of filtered $(28-48 \mathrm{~Hz})$ auditory evoked gamma oscillatory responses of all groups at the TeA1 electrode location. Evoked gamma responses were significantly decreased in all $A \beta_{1-42}$ treated groups compared to Sham group. 



\section{Authors' Responses to Reviewers}

We thank the reviewers for critical reading of the paper and helpful comments. We performed the required corrections and improved the relevant sections to address their questions and comments point-by-point. So, we hope that the responses have the potential to match these questions satisfactorily.

\section{Sincerely}

\section{Corresponding Author}

\section{$\underline{\text { Reviewer \#1: }}$}

1. Authors have revised manusript according to reviewers' comments. The paper can be accepted for further processing in the revised version.

Response: Thank you for your contributions and thoughts.

\section{Reviewer \#3:}

1. The article has been corrected as recommended. The work is interesting and presents new information. The presented work has great potential in terms of further research development. Currently, the work in the form presented can be accepted for printing.

Response: Thank you for your contributions and thoughts.

Reviewer \#5: The authors have adequately addressed my concerns, thus improving the quality of this manuscript. I do not have further requests, except for a minor remark. Regarding the transcranial magnetic stimulation studies in $A D$, the authors report three old studies only (Alagona, et al, 2004; Ferreri, et al. 2003; Pennisi, et al. 2002). I suggest to replace them with a more recent and comprehensive review (i.e. Pennisi G, et al. J Neural Transm 2011), which includes also the three aforementioned studies. 
Response: Thank you for your contributions and thoughts. And also, we performed necessary corrections in line with your comment. We added a sentence as seen below.

"In addition, it was reported that transcranial magnetic stimulation (TMS) techniques have an important role in the detailed assessment of the neurophysiological mechanisms underlying AD. As a result of these studies, it is hypothesized that $\mathrm{AD}$ is thought to be a complex neurodegenerative disease involving different neurotransmitter systems [42]”.

[42] Pennisi G, Ferri R, Lanza G, Cantone M, Pennisi M, Puglisi V, et al. Transcranial magnetic stimulation in Alzheimer's disease: a neurophysiological marker of cortical hyperexcitability. J Neural Transm (Vienna). 2011;118:587-98. 


\section{Conflict of interest}

The authors declare no conflicts of interest.

\section{Financial disclosure}

This research was supported by the Scientific and Technological Research Council of Turkey (TUBITAK) (SBAG 315S054). 
Fig. 1
Click here to download high resolution image

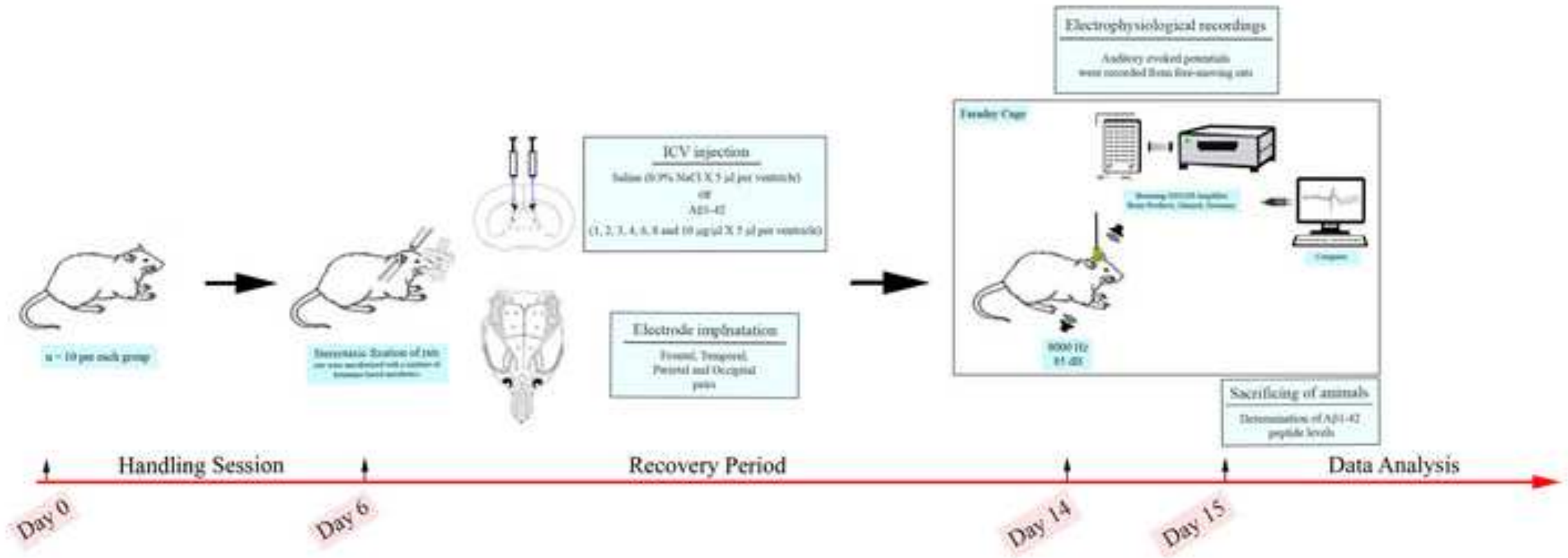


$* * *$

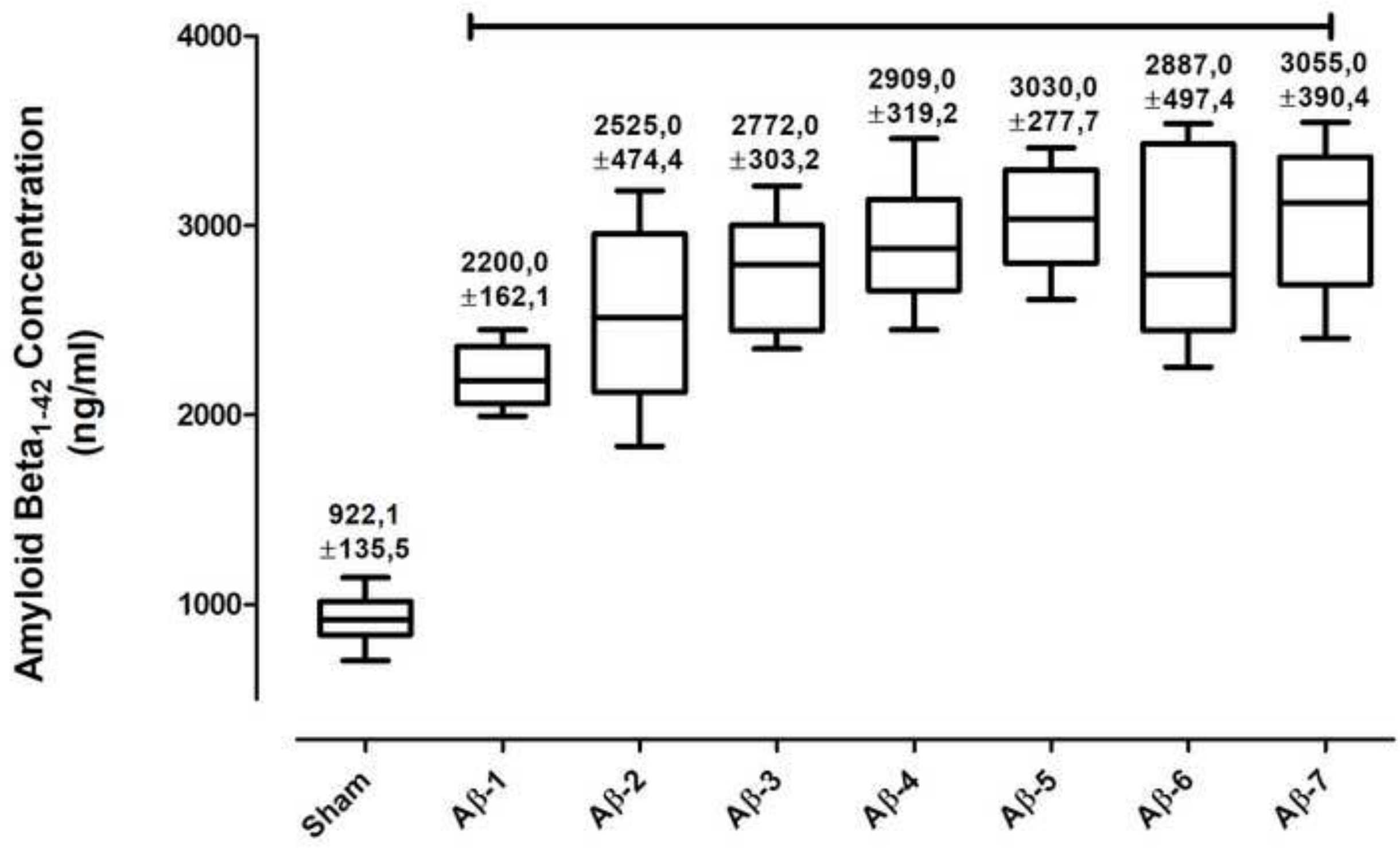




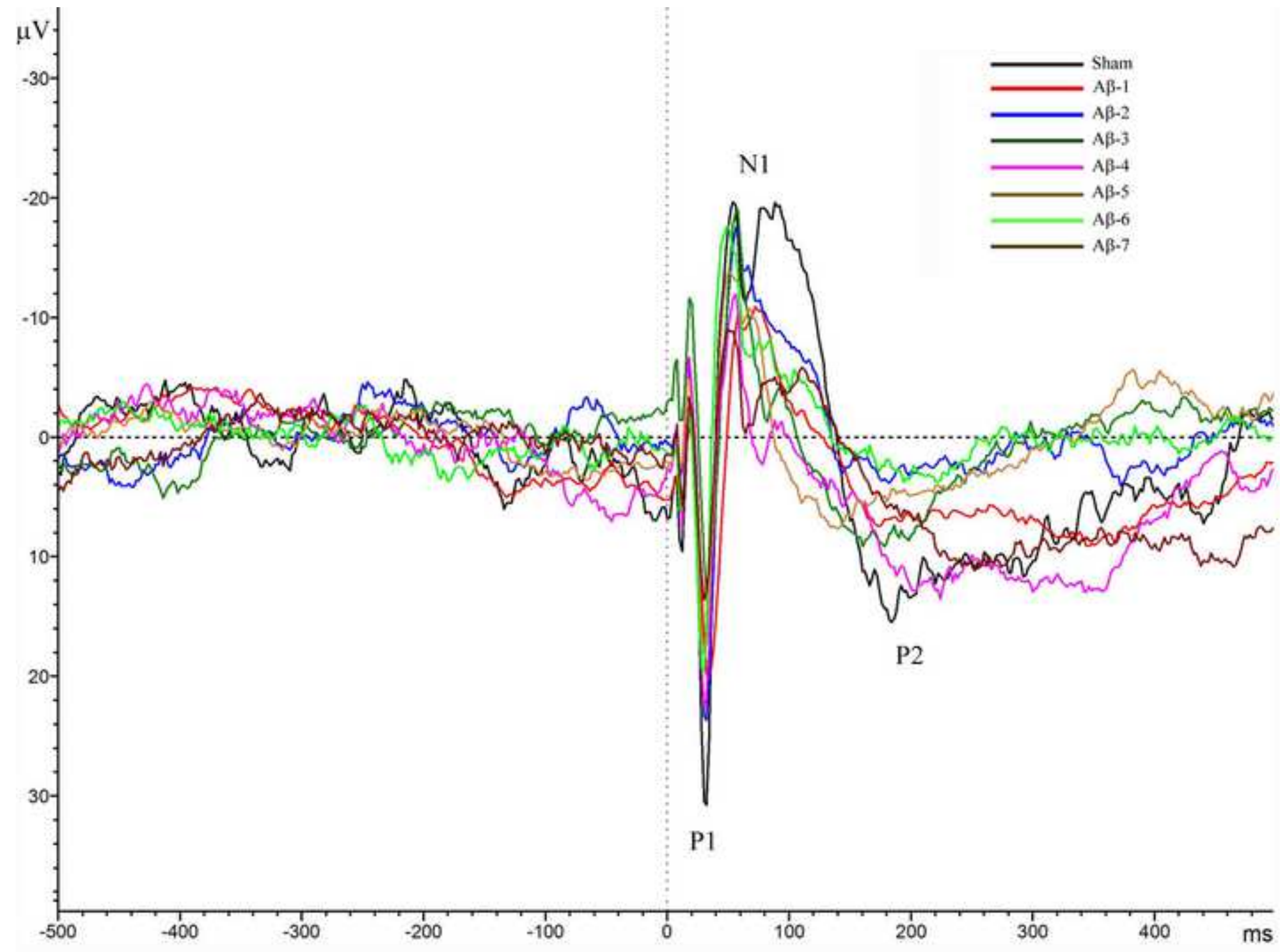


Fig. 4
Click here to download high resolution image
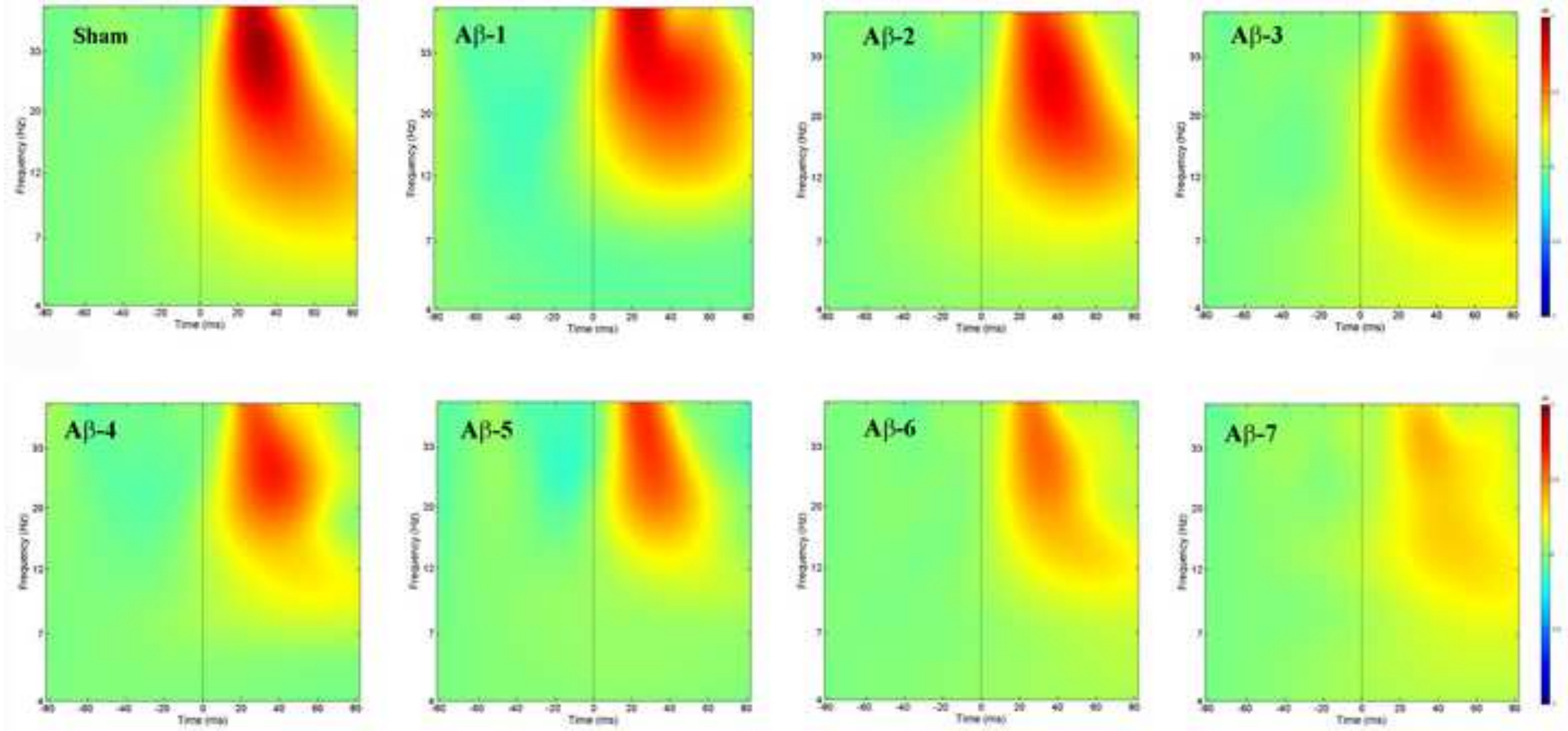
Fig. 5
Click here to download high resolution image
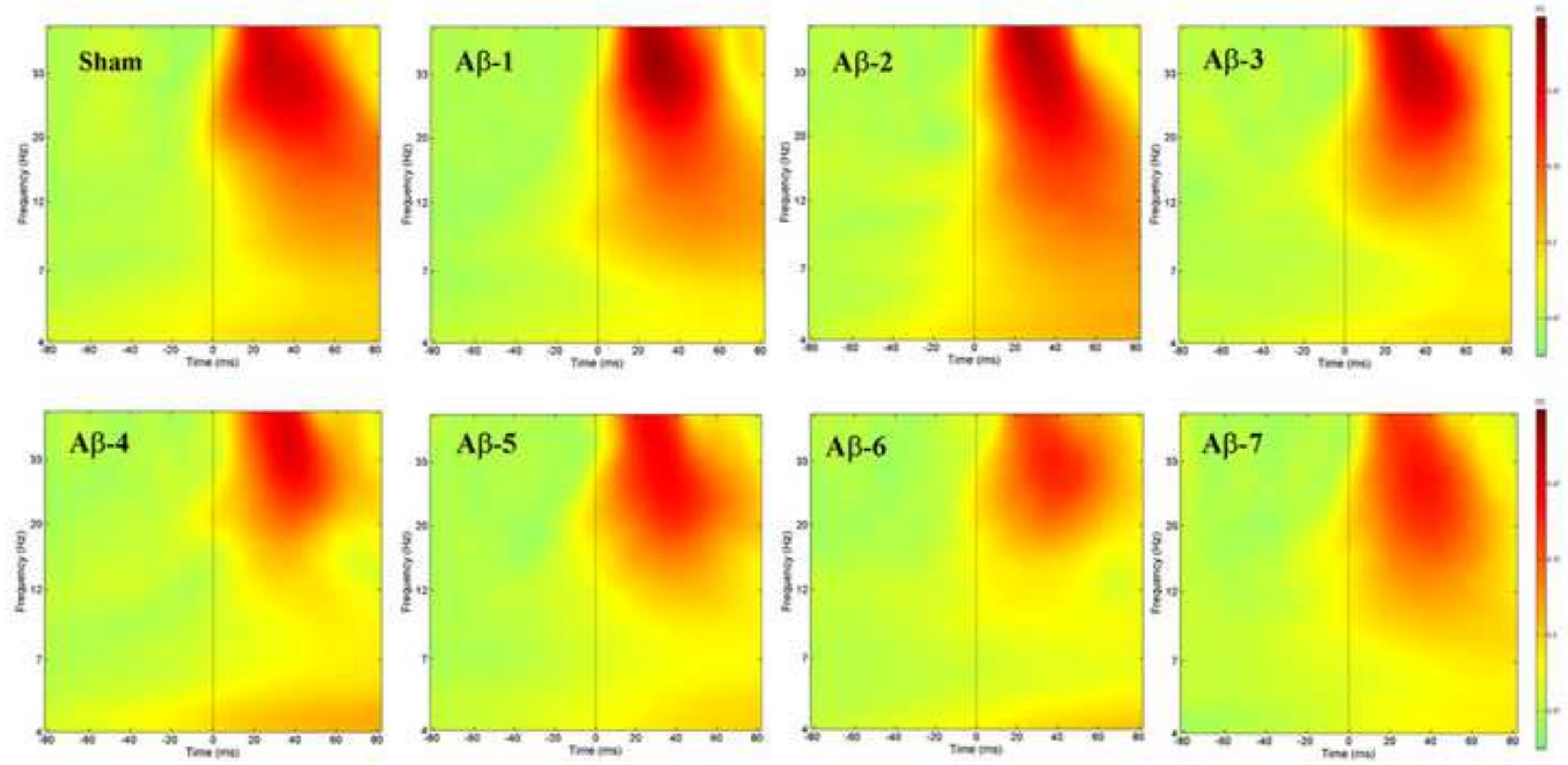
Click here to download high resolution image

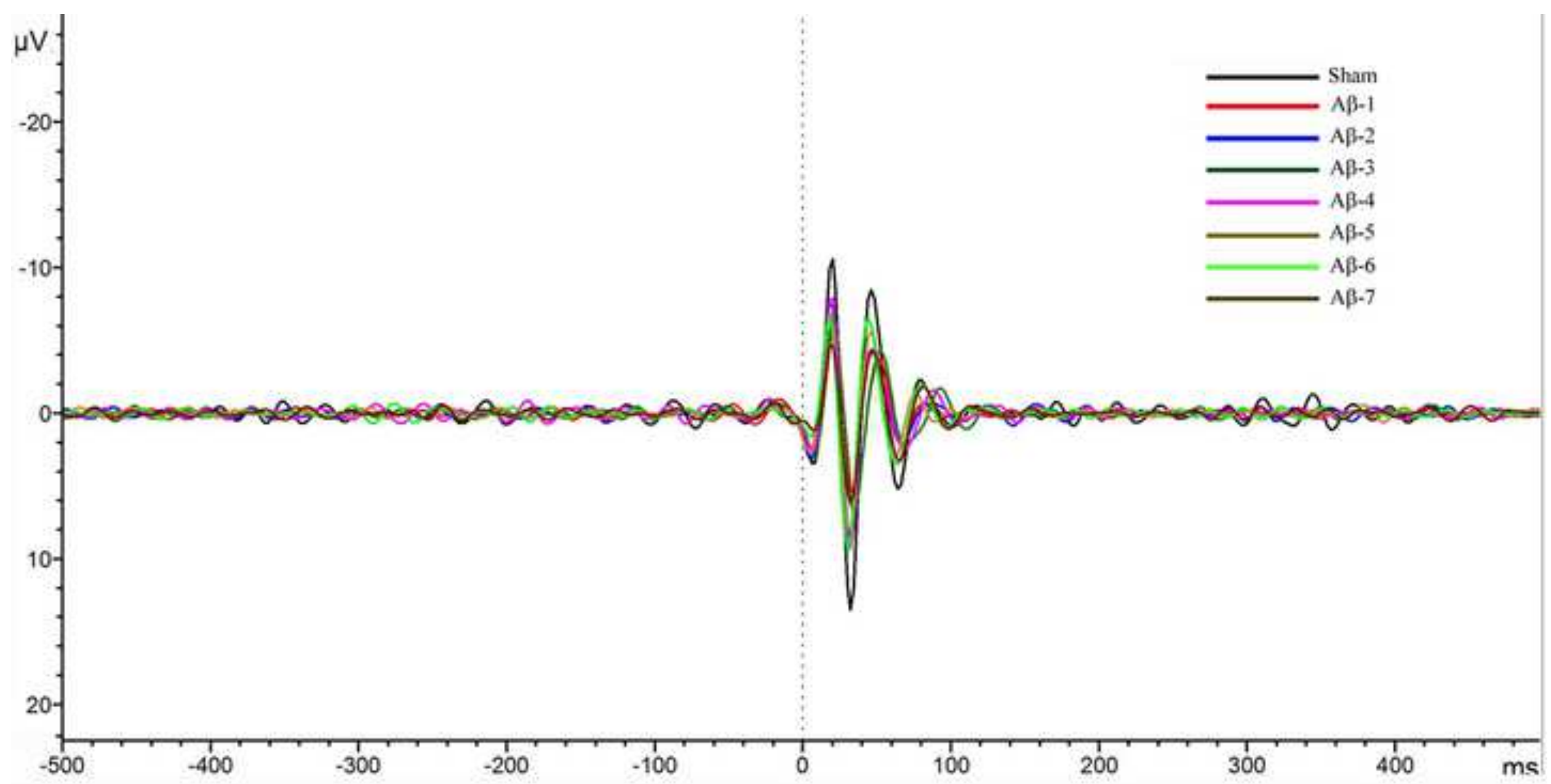


Tab. 1. The means and standard deviations of peak latencies of AEP components in Sham and A $\beta$ groups. There was no main group effect in terms of peak latencies of AEPs components between all groups.

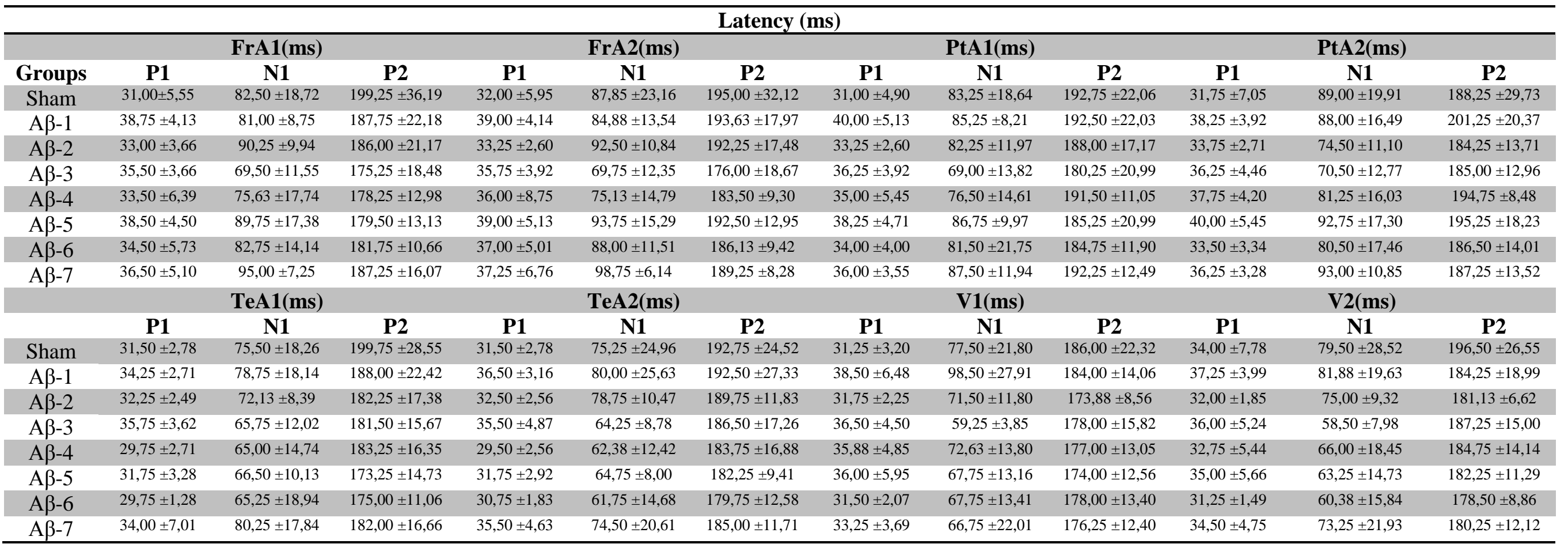


Tab. 2. The means and standard deviations of peak-to-peak amplitudes of AEP components in Sham and A $\beta$ groups. Bold indicates a significant difference in $\mathrm{A} \beta$ groups compared with the Sham group (Greenhouse-Geisser corrected, $\mathrm{p}<0.001)$

\begin{tabular}{|c|c|c|c|c|c|c|c|c|}
\hline \multicolumn{9}{|c|}{ Peak-to-peak Amplitudes $(\mu \mathrm{V})$} \\
\hline & \multicolumn{2}{|c|}{$\operatorname{FrA1}(\mu V)$} & \multicolumn{2}{|c|}{$\operatorname{FrA2}(\mu V)$} & \multicolumn{2}{|c|}{$\operatorname{PtA1}(\mu \mathrm{V})$} & \multicolumn{2}{|c|}{$\overline{\operatorname{PtA} 2(\mu V)}$} \\
\hline Groups & P1N1 & N1P2 & P1N1 & N1P2 & P1N1 & N1P2 & P1N1 & N1P2 \\
\hline Sham & $55,26 \pm 20,32$ & $34,52 \pm 7,82$ & $55,11 \pm 26,12$ & $33,16 \pm 13,34$ & $54,94 \pm 24,01$ & $27,27 \pm 8,93$ & $58,94 \pm 31,89$ & $32,73 \pm 19,05$ \\
\hline $\mathbf{A} \beta-1$ & $39,30 \pm 16,37$ & $17,12 \pm 9,31$ & $39,41 \pm 16,76$ & $16,68 \pm 7,56$ & $39,56 \pm 15,29$ & $16,24 \pm 8,81$ & $45,10 \pm 23,90$ & $18,45 \pm 11,59$ \\
\hline $\mathbf{A} \boldsymbol{\beta}-2$ & $32,56 \pm 8,71$ & $12,48 \pm 5,16$ & $30,14 \pm 7,25$ & $10,49 \pm 5,53$ & $36,27 \pm 13,32$ & $15,60 \pm 8,69$ & $32,10 \pm 11,74$ & $13,62 \pm 5,06$ \\
\hline $\mathbf{A} \boldsymbol{\beta}-\mathbf{3}$ & $26,96 \pm 7,61$ & $11,60 \pm 6,66$ & $25,98 \pm 7,31$ & $12,38 \pm 6,17$ & $29,18 \pm 5,82$ & $18,64 \pm 8,87$ & $32,91 \pm 5,21$ & $15,65 \pm 7,92$ \\
\hline$A \beta-4$ & $28,39 \pm 9,92$ & $15,06 \pm 7,77$ & $34,75 \pm 8,93$ & $14,06 \pm 6,87$ & $30,47 \pm 11,69$ & $16,38 \pm 12,16$ & $28,05 \pm 8,85$ & $15,26 \pm 7,06$ \\
\hline $\mathbf{A} \boldsymbol{\beta}-\mathbf{5}$ & $29,69 \pm 7,35$ & $10,20 \pm 5,12$ & $23,80 \pm 5,64$ & $6,12 \pm 3,48$ & $32,83 \pm 8,19$ & $11,34 \pm 7,64$ & $29,16 \pm 10,15$ & $10,77 \pm 4,02$ \\
\hline$A \beta-6$ & $29,90 \pm 15,58$ & $17,91 \pm 9,17$ & $29,68 \pm 16,97$ & $13,57 \pm 6,18$ & $25,84 \pm 9,72$ & $14,47 \pm 7,69$ & $28,73 \pm 10,74$ & $13,16 \pm 9,26$ \\
\hline \multirow[t]{2}{*}{$\mathbf{A} \beta-7$} & $49,87 \pm 18,17$ & $24,66 \pm 12,20$ & $36,93 \pm 16,93$ & $16,68 \pm 8,71$ & $42,48 \pm 14,36$ & $19,58 \pm 7,85$ & $35,56 \pm 20,75$ & $12,80 \pm 8,97$ \\
\hline & \multicolumn{2}{|c|}{$\operatorname{TeA1}(\mu \mathrm{V})$} & \multicolumn{2}{|c|}{$\operatorname{TeA} 2(\mu \mathrm{V})$} & \multicolumn{2}{|c|}{$\mathrm{V} 1(\mu \mathrm{V})$} & \multicolumn{2}{|c|}{$\mathrm{V} 2(\mu \mathrm{V})$} \\
\hline Groups & P1N1 & N1P2 & P1N1 & N1P2 & P1N1 & N1P2 & P1N1 & N1P2 \\
\hline Sham & $64,83 \pm 30,53$ & $48,96 \pm 26,76$ & $68,28 \pm 36,52$ & $51,76 \pm 35,62$ & $30,30 \pm 19,50$ & $22,69 \pm 12,66$ & $33,79 \pm 20,79$ & $21,54 \pm 15,35$ \\
\hline $\mathbf{A} \beta-1$ & $40,18 \pm 19,16$ & $28,11 \pm 12,66$ & $40,79 \pm 19,12$ & $29,45 \pm 11,62$ & $17,02 \pm 11,47$ & $6,55 \pm 3,87$ & $15,99 \pm 4,56$ & $11,89 \pm 8,17$ \\
\hline$A \beta-2$ & $38,92 \pm 12,16$ & $20,13 \pm 8,62$ & $39,30 \pm 9,76$ & $20,77 \pm 8,08$ & $19,18 \pm 9,17$ & $12,82 \pm 7,47$ & $17,00 \pm 5,14$ & $7,32 \pm 2,89$ \\
\hline $\mathbf{A} \boldsymbol{\beta}-\mathbf{3}$ & $\mathbf{3 0 , 7 2} \pm 8,07$ & $24,74 \pm 10,26$ & $31,10 \pm 8,24$ & $23,14 \pm 7,82$ & $19,57 \pm 4,64$ & $10,29 \pm 4,09$ & $21,25 \pm 9,22$ & $10,86 \pm 8,54$ \\
\hline$A \beta-4$ & $33,63 \pm 14,81$ & $25,12 \pm 18,80$ & $37,32 \pm 10,88$ & $23,60 \pm 13,45$ & $18,49 \pm 4,84$ & $9,97 \pm 4,01$ & $20,41 \pm 7,34$ & $9,56 \pm 4,29$ \\
\hline $\mathbf{A} \boldsymbol{\beta}-5$ & $29,79 \pm 12,04$ & $17,58 \pm 10,16$ & $31,87 \pm 8,67$ & $20,38 \pm 8,99$ & $16,87 \pm 6,22$ & $7,16 \pm 5,58$ & $14,07 \pm 5,69$ & $8,40 \pm 3,89$ \\
\hline$A \beta-6$ & $38,28 \pm 12,36$ & $21,88 \pm 16,16$ & $35,83 \pm 14,72$ & $20,81 \pm 16,72$ & $21,29 \pm 6,21$ & $10,90 \pm 6,00$ & $28,89 \pm 11,49$ & $17,38 \pm 11,97$ \\
\hline $\mathbf{A} \boldsymbol{\beta}-7$ & $24,16 \pm 13,48$ & $19,93 \pm 9,45$ & $23,12 \pm 14,42$ & $19,88 \pm 11,43$ & $15,27 \pm 7,85$ & $9,90 \pm 4,08$ & $15,58 \pm 13,92$ & $8,64 \pm 8,04$ \\
\hline
\end{tabular}


Tab. 3

Tab. 3. Means and standard deviations of maximum gamma band spectrograms values of AEPs in Sham and $A \beta$ groups. Bold indicates a significant difference compared to the Sham (Greenhouse-Geisser corrected, $\mathrm{p}<$ 0.001).

\begin{tabular}{ccccccccc}
\hline Groups & FrA1 & FrA2 & PtA1 & PtA2 & TeA1 & TeA2 & V1 & V2 \\
\hline Sham & $5,30 \pm 2,72$ & $4,91 \pm 1,82$ & $6,10 \pm 1,78$ & $5,14 \pm 0,95$ & $5,77 \pm 1,53$ & $5,84 \pm 1,94$ & $4,89 \pm 2,31$ & $5,69 \pm 1,99$ \\
\hline A $\beta-1$ & $4,90 \pm 1,99$ & $4,20 \pm 1,59$ & $4,64 \pm 1,70$ & $5,09 \pm 2,15$ & $5,00 \pm 1,65$ & $5,20 \pm 2,32$ & $4,21 \pm 1,49$ & $5,14 \pm 1,52$ \\
\hline A $\beta-2$ & $4,05 \pm 1,70$ & $3,97 \pm 1,83$ & $4,56 \pm 1,50$ & $4,34 \pm 1,68$ & $4,84 \pm 2,28$ & $5,26 \pm 1,23$ & $3,81 \pm 1,36$ & $5,06 \pm 1,95$ \\
\hline A $\beta-3$ & $3,61 \pm 1,64$ & $3,51 \pm 1,66$ & $4,47 \pm 1,95$ & $4,24 \pm 1,63$ & $4,84 \pm 1,34$ & $4,85 \pm 1,65$ & $3,65 \pm 1,57$ & $4,88 \pm 1,60$ \\
\hline A $\beta-4$ & $\mathbf{3 , 5 6} \pm \mathbf{2 , 0 3}$ & $\mathbf{3 , 5 1} \pm \mathbf{1 , 6 3}$ & $\mathbf{4 , 1 3} \pm \mathbf{1 , 3 5}$ & $\mathbf{4 , 0 2} \pm \mathbf{1 , 7 6}$ & $\mathbf{4 , 4 8} \pm \mathbf{2 , 0 2}$ & $\mathbf{4 , 7 6} \pm \mathbf{2 , 2 3}$ & $\mathbf{3 , 2 9} \pm \mathbf{0 , 9 8}$ & $\mathbf{4 , 7 2} \pm \mathbf{1 , 8 8}$ \\
\hline A $\beta-5$ & $\mathbf{3 , 5 6} \pm \mathbf{1 , 1 7}$ & $\mathbf{3 , 5 2} \pm \mathbf{2 , 5 7}$ & $\mathbf{3 , 6 7} \pm \mathbf{2 , 6 7}$ & $\mathbf{3 , 9 4} \pm \mathbf{2 , 0 2}$ & $\mathbf{4 , 4 1} \pm \mathbf{1 , 0 5}$ & $\mathbf{4 , 6 4} \pm \mathbf{1 , 0 4}$ & $\mathbf{3 , 1 9} \pm \mathbf{1 , 6 7}$ & $\mathbf{4 , 8 6} \pm \mathbf{1 , 7 2}$ \\
\hline A $\beta-6$ & $\mathbf{3 , 0 0} \pm \mathbf{1 , 5 0}$ & $\mathbf{3 , 0 5} \pm \mathbf{1 , 5 1}$ & $\mathbf{3 , 5 7} \pm \mathbf{2 , 0 6}$ & $\mathbf{3 , 5 2} \pm \mathbf{1 , 3 3}$ & $\mathbf{4 , 5 7} \pm \mathbf{1 , 7 6}$ & $\mathbf{4 , 5 3} \pm \mathbf{1 , 9 5}$ & $\mathbf{3 , 2 5} \pm \mathbf{1 , 5 2}$ & $\mathbf{3 , 8 5} \pm \mathbf{2 , 0 0}$ \\
\hline A $\beta-7$ & $\mathbf{2 , 5 0} \pm \mathbf{0 , 7 9}$ & $\mathbf{2 , 7 3} \pm \mathbf{0 , 8 4}$ & $\mathbf{3 , 1 7} \pm \mathbf{1 , 2 5}$ & $\mathbf{2 , 9 4} \pm \mathbf{1 , 7 1}$ & $\mathbf{4 , 1 3} \pm \mathbf{1 , 6 5}$ & $\mathbf{4 , 0 3} \pm \mathbf{1 , 4 4}$ & $\mathbf{3 , 1 0} \pm \mathbf{1 , 5 2}$ & $\mathbf{3 , 8 3} \pm \mathbf{1 , 7 8}$ \\
\hline
\end{tabular}


Tab. 4. Means and standard deviations of maximum gamma band ITC values of AEPs in Sham and A $\beta$ groups. Bold indicates a significant difference compared to the Sham (Greenhouse-Geisser corrected, $p$ $<0.001$ ).

\begin{tabular}{ccccccccc}
\hline Groups & FrA1 & FrA2 & PtA1 & PtA2 & TeA1 & TeA2 & V1 & V2 \\
\hline Sham & $0,22 \pm 0,05$ & $0,21 \pm 0,05$ & $0,27 \pm 0,05$ & $0,25 \pm 0,03$ & $0,22 \pm 0,09$ & $0,21 \pm 0,09$ & $0,24 \pm 0,10$ & $0,24 \pm 0,09$ \\
\hline $\mathrm{A} \beta-1$ & $0,22 \pm 0,07$ & $0,21 \pm 0,05$ & $0,24 \pm 0,09$ & $0,24 \pm 0,10$ & $0,22 \pm 0,07$ & $0,22 \pm 0,06$ & $0,21 \pm 0,04$ & $0,23 \pm 0,06$ \\
\hline $\mathrm{A} \beta-2$ & $0,19 \pm 0,06$ & $0,20 \pm 0,07$ & $0,23 \pm 0,07$ & $0,22 \pm 0,05$ & $0,20 \pm 0,04$ & $0,20 \pm 0,06$ & $0,20 \pm 0,05$ & $0,22 \pm 0,06$ \\
\hline $\mathrm{A} \beta-3$ & $0,16 \pm 0,04$ & $0,17 \pm 0,05$ & $0,22 \pm 0,06$ & $0,20 \pm 0,07$ & $0,20 \pm 0,07$ & $0,19 \pm 0,06$ & $0,20 \pm 0,03$ & $0,20 \pm 0,04$ \\
\hline $\mathrm{A} \beta-4$ & $\mathbf{0 , 1 7} \pm \mathbf{0 , 0 4}$ & $\mathbf{0 , 1 6} \pm \mathbf{0 , 0 8}$ & $\mathbf{0 , 2 0} \pm \mathbf{0 , 0 6}$ & $\mathbf{0 , 2 0} \pm \mathbf{0 , 0 6}$ & $\mathbf{0 , 1 9} \pm \mathbf{0 , 0 5}$ & $\mathbf{0 , 1 9} \pm \mathbf{0 , 0 4}$ & $\mathbf{0 , 2 0} \pm \mathbf{0 , 0 6}$ & $\mathbf{0 , 2 0} \pm \mathbf{0 , 0 6}$ \\
\hline $\mathrm{A} \beta-5$ & $\mathbf{0 , 1 6} \pm \mathbf{0 , 0 6}$ & $\mathbf{0 , 1 5} \pm \mathbf{0 , 0 8}$ & $\mathbf{0 , 1 9} \pm \mathbf{0 , 0 5}$ & $\mathbf{0 , 1 8} \pm \mathbf{0 , 0 7}$ & $\mathbf{0 , 1 8} \pm \mathbf{0 , 0 5}$ & $\mathbf{0 , 1 8} \pm \mathbf{0 , 0 3}$ & $\mathbf{0 , 1 6} \pm \mathbf{0 , 0 3}$ & $\mathbf{0 , 2 0} \pm \mathbf{0 , 0 4}$ \\
\hline $\mathrm{A} \beta-6$ & $\mathbf{0 , 1 5} \pm \mathbf{0 , 0 6}$ & $\mathbf{0 , 1 4} \pm \mathbf{0 , 0 5}$ & $\mathbf{0 , 1 7} \pm \mathbf{0 , 0 7}$ & $\mathbf{0 , 1 7} \pm \mathbf{0 , 0 7}$ & $\mathbf{0 , 1 7} \pm \mathbf{0 , 0 6}$ & $\mathbf{0 , 1 7} \pm \mathbf{0 , 0 4}$ & $\mathbf{0 , 1 6} \pm \mathbf{0 , 0 8}$ & $\mathbf{0 , 1 8} \pm \mathbf{0 , 0 6}$ \\
\hline $\mathrm{A} \boldsymbol{\beta}-7$ & $\mathbf{0 , 1 4} \pm \mathbf{0 , 0 4}$ & $\mathbf{0 , 1 4} \pm \mathbf{0 , 0 4}$ & $\mathbf{0 , 1 6} \pm \mathbf{0 , 0 4}$ & $\mathbf{0 , 1 4} \pm \mathbf{0 , 0 8}$ & $\mathbf{0 , 1 7} \pm \mathbf{0 , 0 4}$ & $\mathbf{0 , 1 6} \pm \mathbf{0 , 0 6}$ & $\mathbf{0 , 1 4} \pm \mathbf{0 , 0 5}$ & $\mathbf{0 , 1 6} \pm \mathbf{0 , 0 5}$ \\
\hline
\end{tabular}


Tab. 5. Means and standard deviations of filtered $(28-48 \mathrm{~Hz})$ auditory evoked gamma oscillatory responses values in Sham and $A \beta$ groups. Bold indicates a significant difference in $A \beta$ groups compared with the Sham group (Greenhouse-Geisser corrected, $\mathrm{p}<0.001$ ). Also, the asterisk indicates a significant difference in $A \beta-7$ group compared to the other $A \beta$ groups (Greenhouse-Geisser corrected, $\mathrm{p}<0.001$ ).

\begin{tabular}{ccccccccc}
\hline Groups & FrA1 & FrA2 & PtA1 & PtA2 & TeA1 & TeA2 & V1 & V2 \\
\hline Sham & $25,98 \pm 10,74$ & $23,96 \pm 11,56$ & $34,87 \pm 11,05$ & $34,95 \pm 15,47$ & $37,95 \pm 8,17$ & $38,71 \pm 9,39$ & $21,88 \pm 13,50$ & $23,37 \pm 13,68$ \\
\hline A $\beta-1$ & $\mathbf{1 1 , 7 1} \pm \mathbf{4 , 1 6}$ & $\mathbf{1 3 , 1 5} \pm \mathbf{4 , 7 7}$ & $\mathbf{1 4 , 1 5} \pm \mathbf{5 , 5 7}$ & $\mathbf{1 6 , 3 8} \pm \mathbf{7 , 8 3}$ & $\mathbf{1 3 , 7 9} \pm \mathbf{5 , 2 8}$ & $\mathbf{1 2 , 0 4} \pm \mathbf{5 , 4 4}$ & $\mathbf{9 , 2 4} \pm \mathbf{3 , 4 7}$ & $\mathbf{8 , 5 2} \pm \mathbf{3 , 6 2}$ \\
\hline A $\beta-2$ & $\mathbf{1 4 , 3 3} \pm \mathbf{3 , 6 5}$ & $\mathbf{1 4 , 3 4} \pm \mathbf{3 , 8 1}$ & $\mathbf{1 6 , 0 0} \pm \mathbf{4 , 8 3}$ & $\mathbf{1 6 , 3 7} \pm \mathbf{2 , 5 4}$ & $\mathbf{1 6 , 2 7} \pm \mathbf{3 , 6 1}$ & $\mathbf{1 5 , 8 1} \pm \mathbf{3 , 2 8}$ & $\mathbf{1 1 , 8 8} \pm \mathbf{5 , 7 1}$ & $\mathbf{9 , 5 1} \pm \mathbf{4 , 4 4}$ \\
\hline A $\beta-3$ & $\mathbf{1 0 , 8 6} \pm \mathbf{4 , 5 9}$ & $\mathbf{1 2 , 0 5} \pm \mathbf{4 , 9 3}$ & $\mathbf{1 3 , 3 0} \pm \mathbf{3 , 5 5}$ & $\mathbf{1 6 , 1 6} \pm \mathbf{5 , 8 2}$ & $\mathbf{1 3 , 8 6} \pm \mathbf{5 , 0 4}$ & $\mathbf{1 4 , 1 3} \pm \mathbf{4 , 8 4}$ & $\mathbf{1 0 , 8 6} \pm \mathbf{3 , 2 6}$ & $\mathbf{1 1 , 2 6} \pm \mathbf{5 , 8 4}$ \\
\hline A $\beta-4$ & $\mathbf{8 , 5 0} \pm \mathbf{4 , 2 4}$ & $\mathbf{8 , 3 6} \pm \mathbf{4 , 4 0}$ & $\mathbf{1 0 , 2 1} \pm \mathbf{5 , 0 9}$ & $\mathbf{1 1 , 1 9} \pm \mathbf{5 , 4 6}$ & $\mathbf{1 0 , 9 9} \pm \mathbf{2 , 9 0}$ & $\mathbf{1 4 , 0 5} \pm \mathbf{3 , 7 2}$ & $\mathbf{9 , 6 4} \pm \mathbf{3 , 9 8}$ & $\mathbf{1 0 , 7 1} \pm \mathbf{3 , 6 2}$ \\
\hline A $\beta-5$ & $\mathbf{1 1 , 3 2} \pm \mathbf{4 , 4 7}$ & $\mathbf{1 0 , 1 9} \pm \mathbf{3 , 1 0}$ & $\mathbf{1 4 , 9 3} \pm \mathbf{4 , 4 3}$ & $\mathbf{1 3 , 5 7} \pm \mathbf{4 , 2 6}$ & $\mathbf{1 4 , 0 9} \pm \mathbf{5 , 1 8}$ & $\mathbf{1 4 , 6 0} \pm \mathbf{4 , 5 7}$ & $\mathbf{9 , 8 2} \pm \mathbf{3 , 6 7}$ & $\mathbf{9 , 0 9} \pm \mathbf{2 , 8 0}$ \\
\hline A $\beta-6$ & $\mathbf{8 , 1 0} \pm \mathbf{3 , 7 8}$ & $\mathbf{8 , 5 3} \pm \mathbf{4 , 6 7}$ & $\mathbf{1 2 , 3 8} \pm \mathbf{6 , 0 3}$ & $\mathbf{1 3 , 8 2} \pm \mathbf{7 , 1 4}$ & $\mathbf{1 6 , 1 3} \pm \mathbf{6 , 5 1}$ & $\mathbf{1 5 , 6 0} \pm \mathbf{6 , 4 8}$ & $\mathbf{1 1 , 2 7} \pm \mathbf{3 , 7 9}$ & $\mathbf{1 2 , 7 9 \pm 5 , 4 2}$ \\
\hline A $\beta-7$ & $\mathbf{7 , 8 4} \pm \mathbf{4 , 5 1}$ & $\mathbf{5 , 3 0} \pm \mathbf{2 , 1 9}$ & $\mathbf{1 2 , 2 4} \pm \mathbf{4 , 3 4}$ & $\mathbf{8 , 0 4} \pm \mathbf{3 , 2 3}$ & $\mathbf{6 , 9 2} \pm \mathbf{2 , 5 3} *$ & $\mathbf{5 , 5 2} \pm \mathbf{2 , 0 2} *$ & $\mathbf{5 , 7 8} \pm \mathbf{2 , 7 2}$ & $\mathbf{4 , 2 9} \pm \mathbf{1 , 1 3}$ \\
\hline
\end{tabular}




\section{AKDENIZ UNIVERSITY MEDICAL SCHOOL Department of Biophysics}

Dear Sir/Madam

Enclosed please find the paper (ADVMS-D-19-00290R1) on the subject of "Auditory evoked potentials might have the potential to serve as early indicators related to amyloid beta peptide toxicity" to be published in the Journal of "Advances in Medical Sciences". We have necessary changes in the article according to the comments of reviewers. We think it is more satisfactory than the last version. Also, we confirm that all figures and tables which use in this paper are original.

In any case, if a question arises on the paper, please do not hesitate to contact me as soon as possible.

Thank you very much for your consideration.

With best regards

Corresponding Author

Enis Hidisoglu

Adress: Dumlupınar Bulvarı, Campus 07070 Antalya, Turkey. 